Review

\title{
Recent updates on GPCR biased agonism
}

\author{
André S. Pupo $^{\mathrm{a}, *}$, Diego A. Duarte ${ }^{\mathrm{b}}$, Vanessa Lima ${ }^{\mathrm{a}, \mathrm{b}}$, Larissa B. Teixeira ${ }^{\mathrm{b}}$, \\ Lucas T. Parreiras-e-Silva ${ }^{\mathrm{b}}$, Claudio M. Costa-Neto ${ }^{\mathrm{b}, *}$ \\ a Department of Pharmacology, Instituto de Biociências, UNESP, Botucatu, SP, Brazil \\ ${ }^{\mathrm{b}}$ Department of Biochemistry and Immunology, Faculty of Medicine at Ribeirão Preto, University of São Paulo, 14049-900 Ribeirão Preto, SP, Brazil
}

\section{A R T I C L E I N F O}

\section{Article history:}

Received 31 October 2015

Received in revised form 27 January 2016

Accepted 28 January 2016

Available online 2 February 2016

\section{Keywords:}

GPCR

7TMR

Functional selectivity

\begin{abstract}
A B S T R A C T
G protein-coupled receptors (GPCRs) are the most important targets for drug discovery and not surprisingly $\sim 40 \%$ of all drugs currently in the market act on these receptors. Currently, one of the most active areas in GPCRs signaling is biased agonism, a phenomenon that occurs when a given ligand is able to preferentially activate one (or some) of the possible signaling pathways. In this review, we highlight the most recent findings about biased agonism, including an extension of this concept to intracellular signaling, allosterism, strategies for assessment and interpretation, and perspectives of therapeutic applications for biased agonists.
\end{abstract}

(c) 2016 Elsevier Ltd. All rights reserved.

\section{Contents}

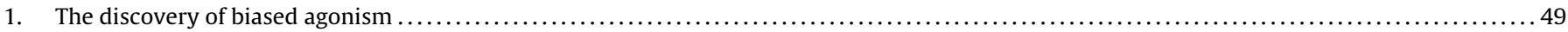

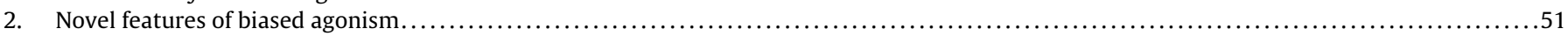

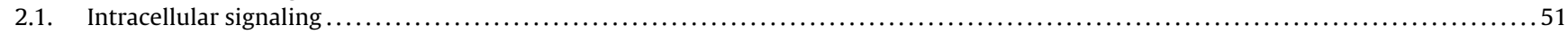

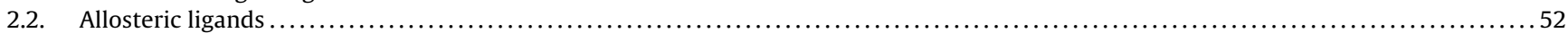

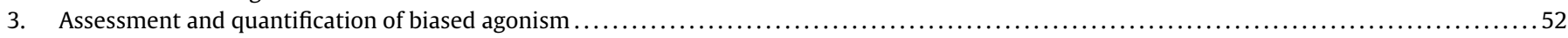

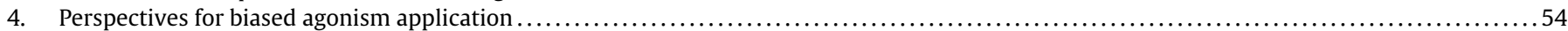

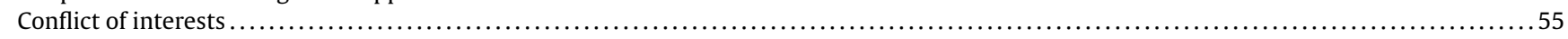

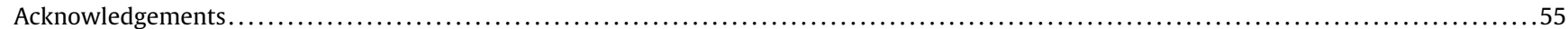

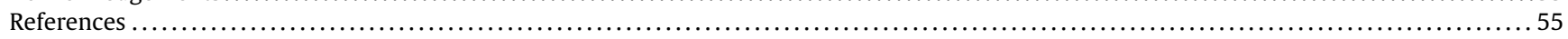

\section{The discovery of biased agonism}

G protein-coupled receptors (GPCRs) are the most important targets for drug discovery and not surprisingly, $40 \%$ of all drugs currently in the market act through GPCRs. As the name suggests, for decades GPCRs were believed to couple only to G proteins, which in turn would activate intracellular effectors such as phospholipase $\mathrm{C}$ or adenylyl cyclase, then modulating the level of intracellular second messengers (e.g., IP3, cAMP). However, in the last decades, GPCRs have also been reported to activate $G$ protein-independent signaling pathways, such as $\beta$-arrestin-dependent activation of ERK1/2 and other kinases $[61,58,15,9,55]$, unveiling the co unveil-

\footnotetext{
* Corresponding author.

E-mail addresses: aspupo@ibb.unesp.br (A.S. Pupo), claudio@fmrp.usp.br (C.M. Costa-Neto).
}

ing the complexity of signaling pathways modulated by such family of receptors. Even more interesting was the discovery of molecules able to trigger only a fraction of the possible responses to be activated by a given GPCR. This led to an update on pharmacological terminology, which besides the so-called "balanced agonists" (Fig. 1A), which are able to indistinguishably activate all those pathways, now it is recognized the existence of ligands that bind to the same GPCR and preferentially activate one of the pathways in detriment of the other and are referred to as "biased agonists" (Fig. 1B and C) $[6,55,34,44,28,73,41,5]$.

Three independent groups published in the beginning of 21st century the first reports of an apparent biased behavior of ligands. Studying the angiotensin AT1 receptor, Robert Lefkowitz's group published in 2003 that an AngII analog, [Sar ${ }^{1}-$ Ile $^{4}-$ Ile $^{8}$ ]-AngII (SII), was unable to activate $G$ protein but could trigger $\beta$-arrestin recruitment and ERK1/2 phosphorylation. Precisely in the same 

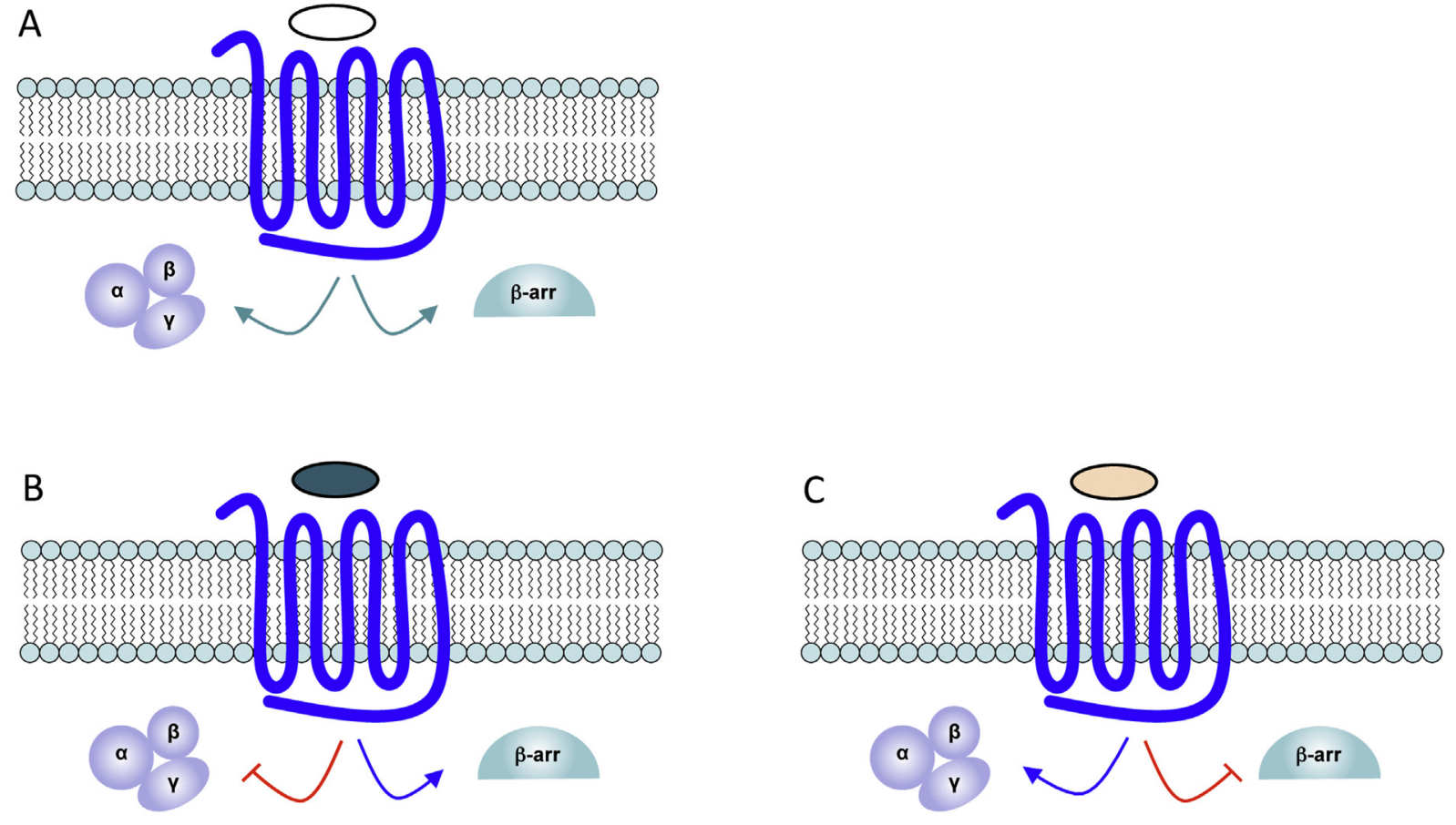

D
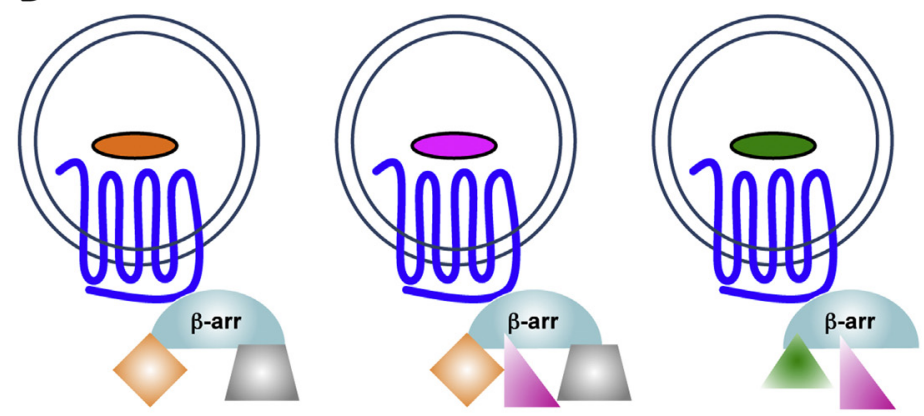

$\mathrm{F}$
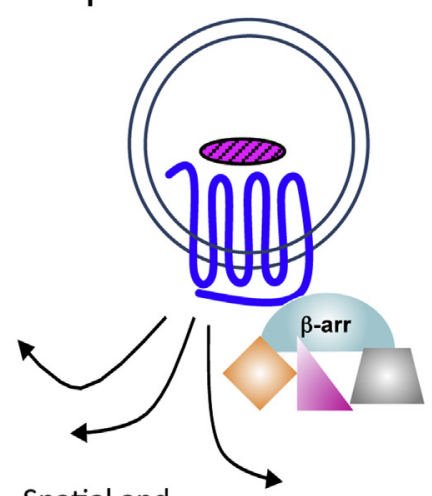

Spatial and temporal bias

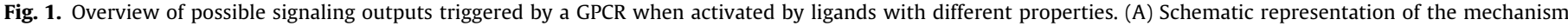

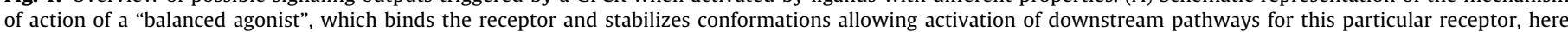

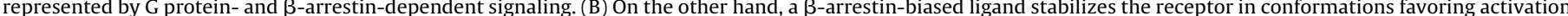

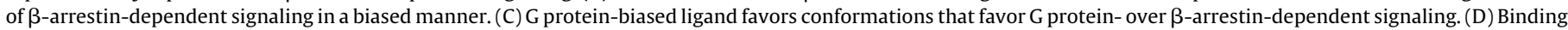

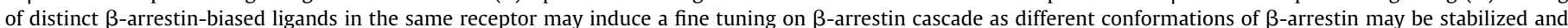

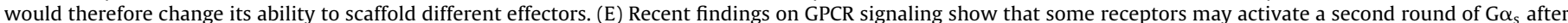

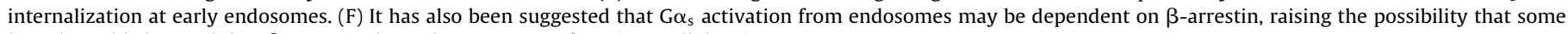
ligands could also modulate $\beta$-arrestin-dependent responses from intracellular sites. 
month, Michel Bouvier's group showed that propranolol, a classical antagonist of the $\beta_{2}$ adrenergic receptor, was actually a $\beta$-arrestin biased agonist [6]. One month later, these findings were corroborated by Stephen Hill's group [7].

Based on the above described findings, it is plausible to expect that some of the clinically used drugs that are generally classified as antagonists can actually behave as biased agonists for one of the signaling pathways. Such "unexpected behavior" of some antagonists could, at least partially, explain the observed distinct outcomes in patients treated with different antagonists for the same receptor. As an example, drugs commonly classified as "beta-blockers" (antagonists for $\beta$-adrenergic receptors) are largely used for treatment of myocardial infarction (e.g. [50]). Interestingly some drugs of this family also show beneficial effects in patients with heart failure, where carvedilol has shown the best results [67,68]. In fact, further studies elucidated that carvedilol actually behaves as a $\beta$-arrestin biased agonist and that ERK activation is involved in the improved therapeutic actions of this compound [87]. On the other hand, biased agonism may also be implicated in undesirable effects, as seems to be the case for the histamine $\mathrm{H} 2$ receptor ligand famotidine, used to treat gastrointestinal ulcers. Famotidine behaves as an inverse agonist for Gs-protein dependent activation of adenylyl cyclase, but act as an agonist for Gs-protein independent effects leading to up-regulation of the expression of histidine decarboxylase and explaining the rebound acid hypersecretion after withdrawal [2]. This further highlights the importance of understanding which clinically used drugs behave as biased agonists, as this pharmacological behavior may either lead to improved or detrimental therapeutics.

The recent concept of biased agonism led to a new paradigm in the receptor theory, where it is now assumed that GPCRs must exist in several distinct conformations [65]. According to this concept, different ligands would be able to stabilize different subsets of receptor conformations, which would then be transmitted to biasedly coupling to and activating a subset of intracellular effectors or a specific effector.

It has been recently reported by us that two $\beta$-arrestin-biased agonists were able to yield distinct patterns of downstream signaling, an effect that probably involved stabilization of different conformations of $\beta$-arrestins [71]. Therefore, it suggests that different ligands - even if they behave as $\beta$-arrestin-biased agonists for instance - are able to induce different conformations of $\beta$-arrestins, which would then be able to scaffold distinct sets of signaling proteins (Fig. 1D). These data highlight the importance of a deeper characterization of lead compounds, because although biased ligands seem to represent a new generation of drugs, an increasing set of recent evidence is unveiling that it might actually comprise more highly complex patterns of functional selectivities than it could be explained just by a simple dichotomy between $G$ protein- or $\beta$-arrestin-dependent signaling pathways.

\section{Novel features of biased agonism}

\subsection{Intracellular signaling}

Until very recently the activation of $G$ protein-dependent signaling pathways has been thought to occur exclusively at the plasma membrane, i.e., the generation of second messengers would be quickly extinguished after receptor phosphorylation by GRKs and $\beta$-arrestin recruitment, which would then result in receptor internalization to endosomes. However, this view has been changed dramatically by accumulated evidence in recent years revealing that some GPCRs may sustain Gs protein signaling and cAMP production in endosomes after internalization of ligand-receptor complexes. This concept was initially described in 2009 for the thyroid-stimulating hormone receptor (TSHR) [14] and parathyroid hormone receptor type 1 (PTHR) [32], and later on it was demonstrated also for other receptors [51,31,40,52,62].

Interestingly, endosomal GPCR signaling via $\mathrm{G}$ proteins may be not only temporally but also spatially distinct from other types of signaling and, therefore, may be considered a new kind of biased signaling. In this case, different ligands can change the duration and location of occurrence of the same signaling pathway, therefore reflecting in differences of second messenger distribution and cellular responses (Fig. 1E) [57,80]. For example, PTH and PTH-related peptide (PTHrP) can modulate the PTHR, which is a crucial receptor for bone development and mineral ion homeostasis, and activate Gs protein-dependent signaling. However, the two ligands differ in dynamics of activation of this pathway, with only PTH leading to sustained cAMP production in early endosomes ( $>30 \mathrm{~min}$ ) after a short exposure to ligand $[32,30]$.

As mentioned before, the generation of cAMP by internalized receptors in endosomes has been reported for other GPCRs such as the dopamine $\mathrm{D} 1$ receptor (D1R) [51], $\beta 2$-adrenergic receptor ( $\beta 2 A R)$ [40], glucagon-like peptide 1 receptor (GLP-1R) [52], pituitary adenylate cyclase activating polypeptide (PACAP) type 1 receptor [62] and vasopressin type 2 receptor (V2R) [31]. In addition, it has been reported endosomal $G$ protein signaling for inhibitory $\mathrm{G}$ protein $(\mathrm{Gi})$-coupled receptors, as shown for the sphingosine-1-phosphate receptor (S1P1R) [64].

The signaling modulated by V2R after stimulation with vasopressin (AVP) and oxytocin (OXT) is an encouraging example that structurally similar ligands can temporally and spatially differently activate the same signaling pathway. Both ligands are cyclic nonapeptides which differ only in two residues; however only AVP leads to persistent cAMP production from early endosomes, whereas cAMP signaling triggered by OXT is believed to be restricted to the plasma membrane [31]. This new mode of signaling explains at least partially the different physiological effects of AVP and OXT on water and electrolyte transport disorders; AVP exerts strong antinatriuretic and antidiuretic effects resulting in sustained water and sodium channels translocation in renal collecting-duct cells, whereas OXT has weak effects, likely due to cAMP production limited to the plasma membrane [17,31].

Although the precise mechanisms controlling this kind of functional selectivity remain to be established, it has been demonstrated that $\beta$-arrestin recruitment to receptor and its internalization are crucial to prolonged generation of cAMP by V2R and PTHR $[32,30]$. Therefore, it is possible to anticipate that some ligands, even stabilizing $\beta$-arrestin with the same scaffold properties, may be able to distinctly modulate, spatially and temporally, the signaling complex (Fig. 1F). In addition, Wehbi et al. [85] showed that the endosomal PTHR signaling arises from a receptor$\beta$-arrestin-G $\beta \gamma$ complex that seems to allow multiple rounds of $\mathrm{G} \alpha$ s subunit association and dissociation, hence generating a high level of active Gas that may or not be bound in the complex.

The prolonged generation of cAMP seems also to arise from differences in affinity of ligands for Gs-uncoupled receptor and for Gs pre-coupled receptor complexes. PTH can form high-affinity complexes with PTHR, which are highly stable and resistant to washout, even in the absence of $G$ protein coupling, enabling sustained cAMP responses from early endosomes. In contrast, PTHrP stabilizes only the conformation of Gs pre-coupled PTHR, forming an unstable complex and triggering a short and transient Gs signaling $[25,79,80]$. It has been demonstrated that PTH analogs with higher affinity than PTH for Gs-uncoupled receptor induce prolonged physiological responses [66,86], an effect attributed to sustained cAMP production. This new concept of GPCR signaling certainly will change the way we think about biased agonism and how we investigate the discovery of novel biased ligands. 


\subsection{Allosteric ligands}

Some molecules have been described to bind GPCRs in allosteric sites, which means that such compounds bind the receptor leading to changes in its conformation and modulating interactions with partners at distinct structural regions, which for a GPCR may be thought as the agonist binding site (orthosteric site) or an effector binding site $[19,20]$. Moreover, some GPCRs may exhibit more than one targetable allosteric site [35]. Allosteric ligands can modulate the affinity of orthosteric ligand for the receptor and/or modulate the ability of the ligand-receptor complex to interact with intracellular effectors [60]. Besides such classical allosteric effects, some allosteric molecules may change orthosteric ligand functional profile, including acting in a biased fashion through binding to allosteric sites and stabilizing receptor conformations more prone to interaction with some effectors than others [48]. For instance, it has been recently shown that the small molecule Org27569 that allosterically bind to $\mathrm{CB}_{1}$ cannabinoid receptor (CB1R) abolished inhibition of cAMP production stimulated for all tested orthosteric ligands, whereas it had no effect on ERK1/2 phosphorylation promoted by some of the ligands tested [47].

Allosteric modulation is an advancing area in GPCR study, leading to new insights in the understanding of structure/function of this pharmacologically important family of membrane receptors. Furthermore, this is also a growing field in GPCR Drug Discovery due to some advantages compared to traditional development of orthosteric binding drugs. The orthosteric binding sites of receptors subtypes for the same ligands are often highly conserved, which limits the specificities of drugs for receptors isoforms, while allosteric modulators bind to sites that are more variable among GPCR subtypes [18,54]. Moreover, weak negative allosteric modulators are thought to be a "new class of antagonists", allowing decreased receptor action without abrogating it, which is of high interest in several diseases in which the basal activity of physiologically important receptors (e.g., neurotransmitter receptors) is exacerbated [20].

Most of the compounds discussed above bind to allosteric sites in the extracellular interface of the receptor. An interesting class of allosteric compounds, described in 2002 [21] which were shown to bind to intracellular allosteric sites of GPCRs, the pepducins, are now of high interest for basic and clinical research [27]. Pepducins are molecules composed of a lipidic and a peptidic moiety, where the peptidic region is usually a 20 -aminoacid stretch resembling the intracellular loops i1, i2 or i3 of a specific GPCR and the lipidic region is often a palmitate group. The use of such intracellular loops peptides are based on reports from early $90 \mathrm{~s}$ describing that such peptides may be of pharmacological relevance $[23,49,74]$. It is believed that, in pepducins, the lipid binds and cross the membrane, allowing the peptide to enter the cell and bind specifically to the intracellular region of the GPCR it interacts with $[22,42]$. Similarly to the extracellular allosteric compounds discussed above, pepducins are able to trigger different pharmacological responses, such as positive, negative and biased modulation of GPCRs' functionality, all of them being of great interest for drug development.

Another exciting perspective concerning the development of allosteric compounds in GPCR Drug Discovery relies on the fact that about 100 GPCRs are still classified as orphan receptors [27], which means that no endogenous ligands are known for them, despite several of these receptors are described to be physiologically important and of pharmacological interest [88,38,59]. In this context, since orphan receptor sequences are known, despite the lack of information about their natural ligands, allosteric compounds become attractive tools for targeting such intriguing GPCRs.

\section{Assessment and quantification of biased agonism}

The most striking manifestations of biased agonism are reversals in orders of potencies (e.g., $\mathrm{pEC}_{50}$ ) and/or efficacies (e.g., maximal effect) for a group of ligands producing responses resultant from activation of a GPCR (Fig. 2). Such reversals are promptly noticeable, but there are more subtle changes in potency and/or efficacy ratios that do not reach absolute reversals and indeed result from biased agonism $[44,29,46]$. In any of these cases, it must be recognized that full log dose/concentration response curves are required for adequate identification and quantification of biased agonism, otherwise the interpretation of results coming from single or only few concentrations of ligands might get confused by simple systemdependent amplification of different cellular stimulus-response cascades.

It is also important to recognize that relevant biased agonism resulting from intrinsic chemical properties of ligands is a relative phenomenon and it is only meaningful if determined in relation to a reference agonist, preferably the endogenous ligand that supposedly triggers all the repertoire of signaling pathways upon receptor activation. Even endogenous ligands show certain degree of "preference" in the activation of discrete signaling pathways in detriment of others and this would be best described by terms like functional selectivity, biased signaling or stimulus trafficking rather than by true biased agonism. For instance, a ligand might be highly efficient in the activation of one signaling pathway in detriment of other pathways, but if all other remaining ligands of this receptor present similar preferences, there is no biased agonism among them. In addition, such functional selectivity in signaling is system-dependent and expected to be highly affected by the stoichiometry of the cellular components involved. If a ligand promotes preferential signaling through $G$ protein rather than through other signaling molecule (e.g., $\beta$-arrestins or GRKs), it is predictable that the degree of preference will change according to the abundance of each of these intracellular interacting partners. In fact, the eel calcitonin is more potent than porcine calcitonin in inducing intracellular calcium transients in HEK293 cells transfected with human calcitonin receptors, but when the cells are enriched with G $\alpha$ s by co-transfection, there is a clear reversal of potency as the porcine calcitonin is more potent than eel calcitonin for the accumulation of cAMP [84]. Therefore, the porcine calcitonin is a biased agonist toward cAMP in comparison to the eel calcitonin only in systems where the calcitonin receptor is strongly coupled to the Gs pathway, otherwise no biased agonism is observed. This type of functional selectivity is difficult to be explored from a therapeutic perspective in reason of system dependence, unless the remote possibility that the same receptor coupling efficiency will be maintained in the target organ.

Artifactual interferences from the method and devices employed to detect GPCR activation may also lead to false functional selectivity (and mistakenly be considered biased agonism). For instance, Fig. 3 shows the ability of noradrenaline and oxymetazoline to activate Gq proteins in HEK293 cells expressing the human $\alpha 1 \mathrm{~A}$-adrenoceptor measured both as intracellular calcium transients (Fig. 3A) and in BRET assay for the dissociation of G $\alpha \mathrm{q}$ from G $\beta \gamma$ complex (Fig. 3B). In this case, oxymetazoline behaved as a partial agonist in relation to noradrenaline in the calcium assay, but was virtually ineffective in the BRET assay for $\mathrm{G} \alpha \mathrm{q}$ dissociation, probably because calcium measurements are events largely amplified by cellular stimulus-response cascade mechanisms, or either because $\mathrm{Gq}$ activation by oxymetazoline may occur in different kinetics when compared to noradrenaline, as is the case for internalization process. In HEK293 cells, short time incubations with oxymetazoline induce rapid phosphorylation and internalization of human $\alpha 1 \mathrm{~A}$-adrenoceptors, whereas much longer incubations are required to promote receptor internalization when the ago- 
agonist $\mathbf{A}$

agonist B

$\searrow$
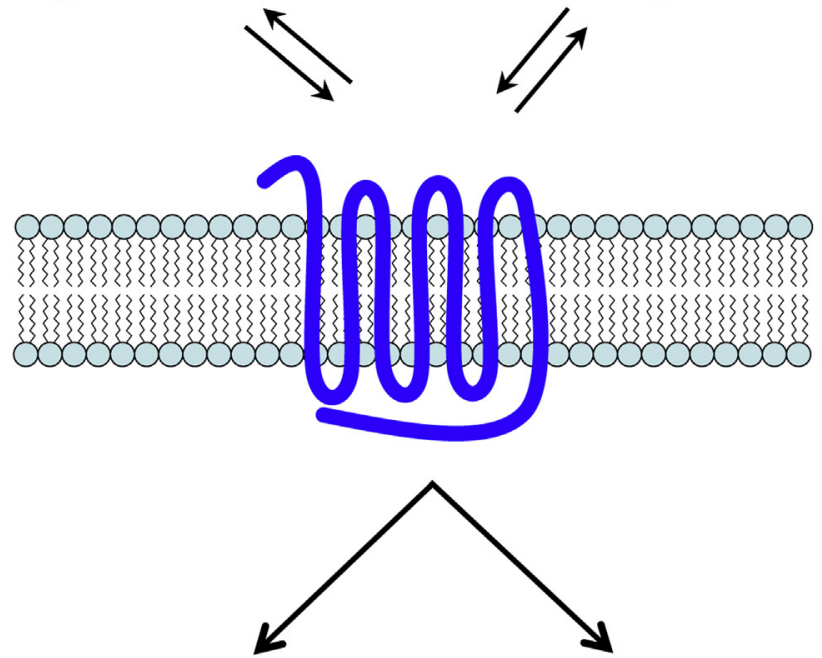

signaling pathway 1

signaling

pathway 2

reversal of potency
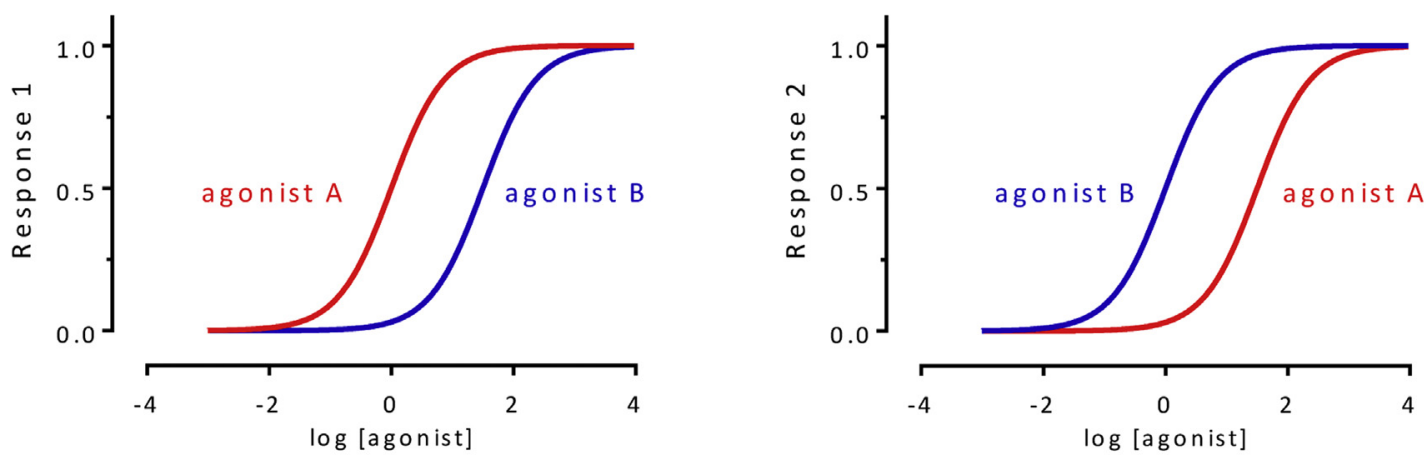

reversal of efficacy
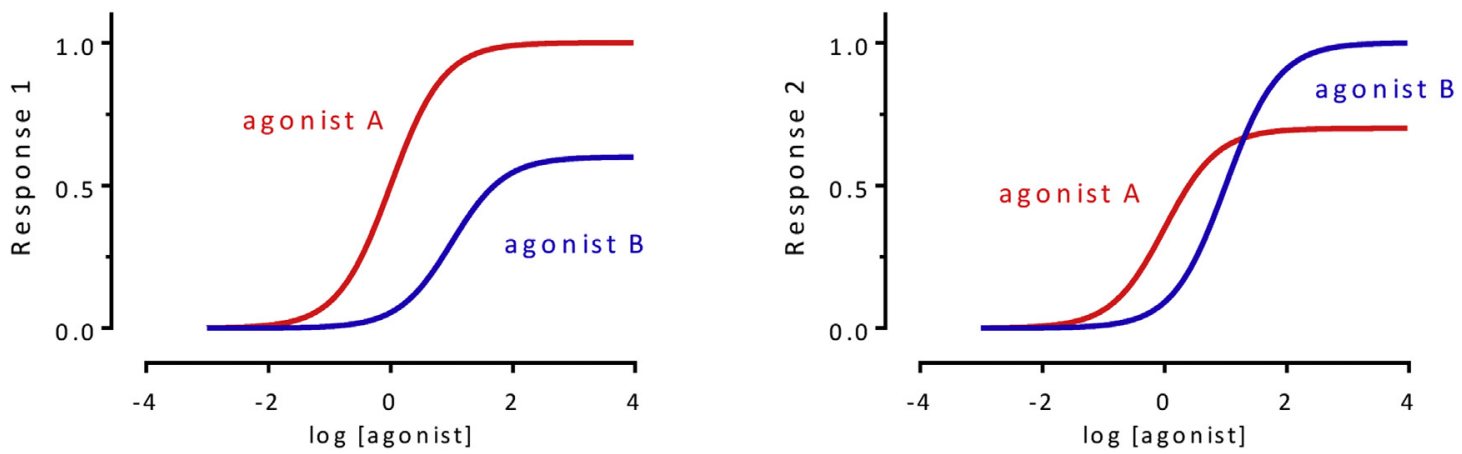

Fig. 2. Schematic representation of differences of potency and efficacy in biased agonism. Agonist A has higher potency/efficacy than agonist B in pathway 1, but lower potency/efficacy than agonist B in pathway 2 . 
A

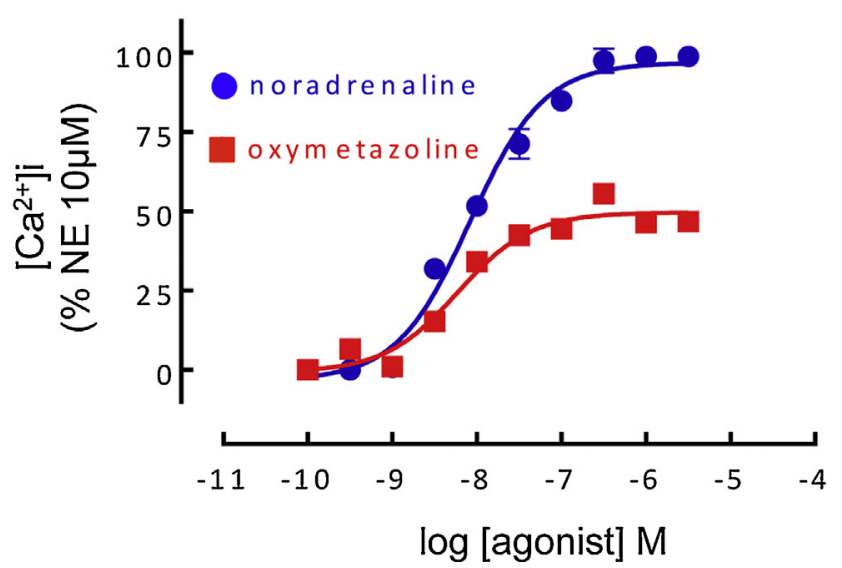

B

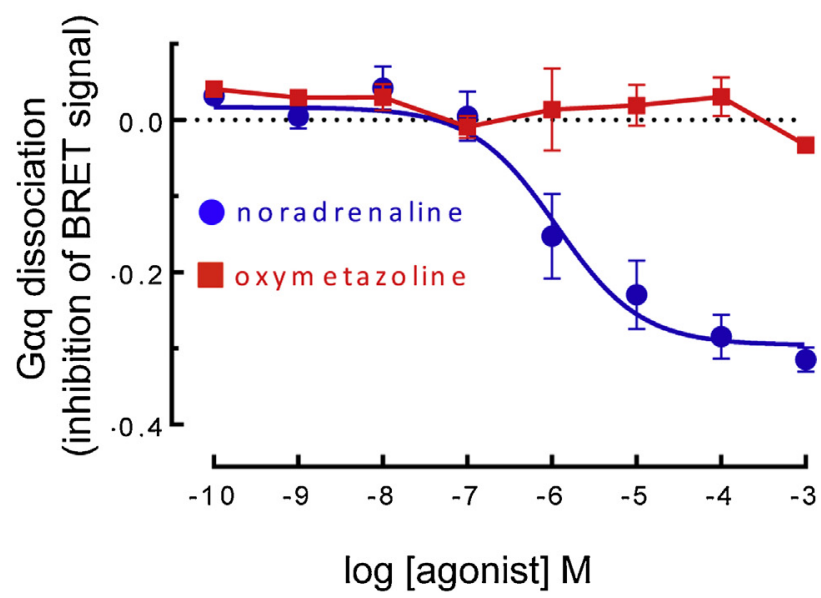

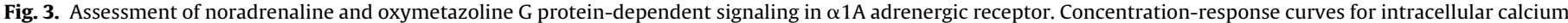

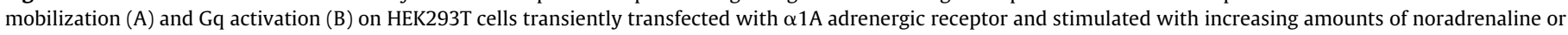
oxymetazoline.

nist is noradrenaline [1]. If concentration-response curves for the internalization induced by oxymetazoline and noradrenaline are performed at $30 \mathrm{~min}$ of agonist incubation, oxymetazoline is considered a full agonist for human $\alpha 1 \mathrm{~A}$-adrenoceptor internalization, whereas noradrenaline is inactive at this specific time point [1], giving the false impression that noradrenaline is absolutely biased toward Gq signaling versus receptor internalization.

Recently, at least three useful pharmacological parameters were proposed for the quantification of biased agonism, the Intrinsic Relative Activity $\left(\mathrm{RA}_{\mathrm{i}},{ }^{2}\right.$ 29] $)$ ratios, the bias factor $\beta$ [70] and the $\log$ Bias or $\Delta \Delta \log \tau / \mathrm{K}_{\mathrm{A}}$ [46]. Because of space constraints, the reader will be referred to the specific literature above for the mathematical grounds of each of them. A common feature of all three parameters is that they relate functional estimates of ligands efficacy and affinity and assume that changes in its ratios in two or more signaling pathways result from agonist directed stabilization of different receptor conformations.

The most straightforward in terms of calculation is the Intrinsic Relative Activity $\left(R A_{i}\right)$ ratio described by [29] that only requires the knowledge of Maximal Effect (Emax) and $\mathrm{pEC}_{50}$ as combined surrogates of efficacy and affinity of agonists in two of the triggered signaling pathways. However, when the Hill coefficients of the log concentration-response curves differ from $1.0, \mathrm{RA}_{\mathrm{i}}$ ratios will be largely affected by cell dependent interferences such as receptor densities and coupling efficiencies (reviewed in Refs. [29,46]) . For the calculation of both the bias factor $\beta[70]$ and the $\Delta \Delta \log \tau / K_{\mathrm{A}}$ [46], the log concentration-response curves for the agonists are analyzed according to the Black-Leff Operational Model of Agonism [10] to provide estimates of efficacy $(\tau)$ and affinity $\left(K_{\mathrm{A}}\right)$. However, one important difference between the bias factor $\beta$ and the $\Delta \Delta \log \tau / K_{\mathrm{A}}$ is that the former uses independent estimates of affinity usually from radioligand binding, whereas the latter accommodates the possibility that different receptor affinity states for the agonist exist in each of the triggered signaling pathways and uses $K_{\mathrm{A}}$ values determined though the Operational Model equation. In fact, it seems more appropriate to let $K_{\mathrm{A}}$ values unconstrained since biased agonism is built on the concept that different ligands will stabilize different receptor conformations favoring the activation of discrete signaling pathways and there is no obvious reason to assume that the ligand will interact with these different receptor conformations presenting similar affinities.

\section{Perspectives for biased agonism application}

Despite the increasing complexity of what can be considered biased agonism as above discussed, discovery of ligand bias, as a general concept of a broader capability of signaling, has raised speculations about the possibility of achieving pharmacological profiles distinct from those classically related to agonists or antagonists [44,83]. Biased agonists so far described have shown ability to emphasize a beneficial cellular signal, to de-emphasize a debilitating signal, or to de-emphasize a debilitating signal while blocking the capacity of the endogenous agonist to produce the signal [45].

The development of novel GPCR drugs with potentially increased efficacy and/or fewer on-target adverse effects has already prompted a few compounds into clinical trials. The first one being tested in humans against an unbiased ligand is TRV130, a $G$ protein biased agonist (versus $\beta$-arrestin-2) that binds to the $\mu$ opioid receptor (MOR) and produces analgesia comparable to that of morphine [16]. Preclinical studies have suggested that opioid analgesia is associated with $\mathrm{G} \alpha_{\mathrm{i}}$ coupling at the MOR, whereas gastrointestinal dysfunction, respiratory depression and tolerance to the analgesic effect are all linked to $\beta$-arrestin- 2 recruitment $[13,12,39,69,56,89,26]$.

On the other side, a potent $\beta$-arrestin biased ligand of the angiotensin II type 1 receptor $\left(\mathrm{AT}_{1} \mathrm{R}\right)$ [82], referred to as TRV027, is currently being investigated in Phase $2 \mathrm{~b}$ as an intravenous drug for the treatment of acute heart failure (AHF) (ClinicalTrials.gov Identifier: NCT01966601). Besides enhancing cardiac contractility and output [82], TRV027 also differs from angiotensin-converting enzyme (ACE) inhibitors and angiotensin receptor blockers (ARBs) by controlling vasoactive effects to prevent prolonged hypotension [81].

Evidence on parallel signaling pathways that could be differentially targeted by biased agonists has accumulated for a great number of GPCRs. A comprehensive list of these receptors is beyond the scope of this review, but a few examples might illustrate the range of biological scenarios for which biased agonists may be of value. For instance, positive therapeutic effects on mnemonic processes in Alzheimer's disease models have been shown for the $\mathrm{G} \alpha_{\mathrm{q}}$-biased agonist pilocarpine, which selectively activates the M1 muscarinic acetylcholine receptor $[33,36]$. Moreover, favoring $\beta$ arrestin-2-dependent recruitment and signaling in the dopamine $D_{2}$ receptor has also been suggested as a potentially important tool for the management of neuropsychiatric disorders, enhancing 
antipsychotic efficacy and protecting against motoric side effects of antidopaminergic drugs [8,3].

As discussed previously, allosteric ligands can also lead to bias signaling in some GPCRs. Because such modulators can provide great subtype selectivity among receptors, they represent interesting opportunities for drug discovery. Cinacalcet corresponds to the first allosteric modulator to make it to the clinic. It was approved by the Food and Drug Administration and by the European Medicines Agency for the treatment of secondary hyperparathyroidism in chronic kidney disease patients. Cinacalcet is a positive allosteric modulator of the calcium-sensing receptor (CaSR) that favors plasma membrane ruffling over calcium signaling and ERK phosphorylation [24]. Although clinically relevant, the drug is not widely used in earlier stages of kidney disease due to its potential to predispose these patients to hypocalcemia. The hypocalcemic side effects are presumably caused by receptor-mediated calcitonin secretion [75]. Therefore, the development of a more selective biased ligand may overcome this usage limitation.

Along the past decade several groups have attempted to combine the advantages of targeting orthosteric and allosteric sites from a GPCR by designing dual specificity agonists, termed "bitopic" ligands. For the successful generation of a bitopic ligand, the orthosteric and the allosteric sites must be in close proximity. Moreover, the allosteric site must be accessible from the orthosteric site $[78,63,77,53,72]$. One of the best-characterized GPCRs in this respect is the M2 muscarinic acetylcholine receptor [37]. The rational design of dualsteric muscarinic agonists has already been accomplished $[4,11]$. Mohr and colleagues pioneered this approach by linking a potent orthosteric activator (iperoxo) with an M2selective allosteric fragment (W84 inhibitor or naphmethonium enhancer) [4]. Applying label-free dynamic mass redistribution technology, the researchers were able to show that these ligands show differential pathway selectivity, as compared to iperoxo and acetylcholine [43]. These studies highlighted the possibility that some biased agonists may achieve their bias through a previously unrecognized bitopic mechanism of interaction. Such a possibility was exemplified by McN-A-343, another M2 biased ligand. McN-A-343 was used as a model to generate two fragments, a high efficacy orthosteric agonist and a negative allosteric modulator. When the fragments were combined, the pharmacology of McN-A-343 could be recapitulated [76]. The increasing amount of structural information regarding ligand-GPCR complexes and allosteric sites makes the rational design of dualsteric drugs a promising new approach to finely modulate receptor responses.

\section{Conflict of interests}

The authors declare no conflicts of interest.

\section{Acknowledgements}

This study is supported by the Sao Paulo State Research Foundation (FAPESP grants 2012/20148-0 and 2008/50423-7).

\section{References}

[1] J. Akinaga, V. Lima, L.R. Kiguti, F. Hebeler-Barbosa, R. Alcantara-Hernandez, J.A. Garcia-Sainz, et al., Differential phosphorylation, desensitization, and internalization of alpha1A-adrenoceptors activated by norepinephrine and oxymetazoline, Mol. Pharmacol. 83 (2013) 870-881, http://dx.doi.org/10. 1124/mol.112.082313.

[2] N. Alonso, C.D. Zappia, M. Cabrera, C.A. Davio, C. Shayo, F. Monczor, N.C. Fernández, Physiological implications of biased signaling at histamine $\mathrm{H} 2$ receptors, Front. Pharmacol. 6 (2015) 45, http://dx.doi.org/10.3389/fphar. 2015.00045.

[3] J.A. Allen, J.M. Yost, V. Setola, X. Chen, M.F. Sassano, M. Chen, et al., Discovery of beta-arrestin-biased dopamine D2 ligands for probing signal transduction pathways essential for antipsychotic efficacy, Proc. Natl. Acad. Sci. U. S. A. 108 (2011) 18488-18493, http://dx.doi.org/10.1073/pnas.1104807108.

[4] J. Antony, K. Kellershohn, M. Mohr-Andra, A. Kebig, S. Prilla, M. Muth, et al., Dualsteric GPCR targeting: a novel route to binding and signaling pathway selectivity, FASEB J. 23 (2009) 442-450, http://dx.doi.org/10.1096/fj.08114751.

[5] M. Audet, M. Bouvier, Restructuring G-protein-coupled receptor activation, Cell 151 (2012) 14-23, http://dx.doi.org/10.1016/j.cell.2012.09.003.

[6] M. Azzi, P.G. Charest, S. Angers, G. Rousseau, T. Kohout, M. Bouvier, et al., Beta-arrestin-mediated activation of MAPK by inverse agonists reveals distinct active conformations for $\mathrm{G}$ protein-coupled receptors, Proc. Natl. Acad. Sci. U. S. A. 100 (2003) 11406-11411, http://dx.doi.org/10.1073/pnas. 1936664100.

[7] J.G. Baker, I.P. Hall, S.J. Hill, Agonist and inverse agonist actions of beta-blockers at the human beta 2-adrenoceptor provide evidence for agonist-directed signaling, Mol. Pharmacol. 64 (2003) 1357-1369, http://dx. doi.org/10.1124/mol.64.6.1357.

[8] J.M. Beaulieu, R.R. Gainetdinov, M.G. Caron, The Akt-GSK-3 signaling cascade in the actions of dopamine, Trends Pharmacol. Sci. 28 (2007) 166-172, http:// dx.doi.org/10.1016/j.tips.2007.02.006.

[9] J.M. Beaulieu, T.D. Sotnikova, S. Marion, R.J. Lefkowitz, R.R. Gainetdinov, M.G Caron, An Akt/beta-arrestin 2/PP2A signaling complex mediates dopaminergic neurotransmission and behavior, Cell 122 (2005) 261-273, http://dx.doi.org/10.1016/j.cell.2005.05.012.

[10] J.W. Black, P. Leff, Operational models of pharmacological agonism, Proc. R. Soc. Lond. B Biol. Sci. 220 (1983) 141-162

[11] A. Bock, N. Merten, R. Schrage, C. Dallanoce, J. Batz, J. Klockner, et al., The allosteric vestibule of a seven transmembrane helical receptor controls G-protein coupling, Nat. Commun. 3 (2012) 1044, http://dx.doi.org/10.1038/ ncomms2028.

[12] L.M. Bohn, R.R. Gainetdinov, F.T. Lin, R.J. Lefkowitz, M.G. Caron, Mu-opioid receptor desensitization by beta-arrestin-2 determines morphine tolerance but not dependence, Nature 408 (2000) 720-723, http://dx.doi.org/10.1038/ 35047086.

[13] L.M. Bohn, R.J. Lefkowitz, R.R. Gainetdinov, K. Peppel, M.G. Caron, F.T. Lin, Enhanced morphine analgesia in mice lacking beta-arrestin 2, Science 286 (1999) 2495-2498

[14] D. Calebiro, V.O. Nikolaev, M.C. Gagliani, T. De Filippis, C. Dees, C. Tacchetti, et al., Persistent cAMP-signals triggered by internalized G-protein-coupled receptors, PLoS Biol. 7 (2009) e1000172, http://dx.doi.org/10.1371/journal. pbio. 1000172 .

[15] P.G. Charest, M. Bouvier, Palmitoylation of the V2 vasopressin receptor carboxyl tail enhances beta-arrestin recruitment leading to efficient receptor endocytosis and ERK1/2 activation, J. Biol. Chem. 278 (2003) 41541-41551, http://dx.doi.org/10.1074/jbc.M306589200.

[16] X.T. Chen, P. Pitis, G. Liu, C. Yuan, D. Gotchev, C.L. Cowan, et al, Structure-activity relationships and discovery of a $G$ protein biased mu opioid receptor ligan. [(3-methoxythiophen-2-yl) methyl](\{2-[(9R)-9-(pyridin-2-yl)-6-oxaspiro-[4.5]decan-9-yl]ethyl $\})$ amine (TRV130), for the treatment of acute severe pain, J. Med. Chem. 56 (2013) 8019-8031, http://dx.doi.org/10.1021/jm4010829.

[17] C.L. Chou, S.R. Digiovanni, R. Mejia, S. Nielsen, M.A. Knepper, Oxytocin as an antidiuretic hormone. I. Concentration dependence of action, Am. J. Physiol. 269 (1995) F70-77.

[18] A. Christopoulos, Allosteric binding sites on cell-surface receptors: novel targets for drug discovery, Nat. Rev. Drug Discov. 1 (2002) 198-210, http://dx. doi.org/10.1038/nrd746.

[19] A. Christopoulos, T. Kenakin, G protein-coupled receptor allosterism and complexing, Pharmacol. Rev. 54 (2002) 323-374.

[20] P.J. Conn, A. Christopoulos, C.W. Lindsley, Allosteric modulators of GPCRs: a novel approach for the treatment of CNS disorders, Nat. Rev. Drug Discov. 8 (2009) 41-54, http://dx.doi.org/10.1038/nrd2760.

[21] L. Covic, A.L. Gresser, J. Talavera, S. Swift, A. Kuliopulos, Activation and inhibition of $G$ protein-coupled receptors by cell-penetrating membrane-tethered peptides, Proc. Natl. Acad. Sci. U. S. A. 99 (2002) 643-648, http://dx.doi.org/10.1073/pnas.022460899.

[22] L. Covic, M. Misra, J. Badar, C. Singh, A. Kuliopulos, Pepducin-based intervention of thrombin-receptor signaling and systemic platelet activation, Nat. Med. 8 (2002) 1161-1165, http://dx.doi.org/10.1038/nm760.

[23] H.M. Dalman, R.R. Neubig, Two peptides from the alpha 2A-adrenergic receptor alter receptor $\mathrm{G}$ protein coupling by distinct mechanisms, J. Biol. Chem. 266 (1991) 11025-11029.

[24] A.E. Davey, K. Leach, C. Valant, A.D. Conigrave, P.M. Sexton, A. Christopoulos Positive and negative allosteric modulators promote biased signaling at the calcium-sensing receptor, Endocrinology 153 (2012) 1232-1241, http://dx. doi.org/10.1210/en.2011-1426.

[25] T. Dean, J.P. Vilardaga, J.T. Potts Jr., T.J. Gardella, Altered selectivity of parathyroid hormone (PTH) and PTH-related protein (PTHrP) for distinct conformations of the PTH/PTHrP receptor, Mol. Endocrinol. 22 (2008) 156-166, http://dx.doi.org/10.1210/me.2007-0274.

[26] S.M. Dewire, D.S. Yamashita, D.H. Rominger, G. Liu, C.L. Cowan, T.M. Graczyk, et al., A G protein-biased ligand at the mu-opioid receptor is potently analgesic with reduced gastrointestinal and respiratory dysfunction compared with morphine, J. Pharmacol. Exp. Ther. 344 (2013) 708-717, http://dx.doi.org/10.1124/jpet.112.201616. 
[27] P. Dimond, K. Carlson, M. Bouvier, C. Gerard, L. Xu, L. Covic, et al., G protein-coupled receptor modulation with pepducins: moving closer to the clinic, Ann. N. Y. Acad. Sci. 1226 (2011) 34-49, http://dx.doi.org/10.1111/j. 1749-6632.2011.06039.x.

[28] M.T. Drake, J.D. Violin, E.J. Whalen, J.W. Wisler, S.K. Shenoy, R.J. Lefkowitz, beta-arrestin-biased agonism at the beta2-adrenergic receptor, J. Biol. Chem. 283 (2008) 5669-5676, http://dx.doi.org/10.1074/jbc.M708118200.

[29] F.J. Ehlert, On the analysis of ligand-directed signaling at G protein-coupled receptors, Naunyn Schmiedebergs Arch. Pharmacol. 377 (2008) 549-577, http://dx.doi.org/10.1007/s00210-008-0260-4.

[30] T.N. Feinstein, V.L. Wehbi, J.A. Ardura, D.S. Wheeler, S. Ferrandon, T.J. Gardella, et al., Retromer terminates the generation of cAMP by internalized PTH receptors, Nat. Chem. Biol. 7 (2011) 278-284, http://dx.doi.org/10.1038/ nchembio.545.

[31] T.N. Feinstein, N. Yui, M.J. Webber, V.L. Wehbi, H.P. Stevenson, J.D. King Jr., et al., Noncanonical control of vasopressin receptor type 2 signaling by retromer and arrestin, J. Biol. Chem. 288 (2013) 27849-27860, http://dx.doi. org/10.1074/jbc.M112.445098.

[32] S. Ferrandon, T.N. Feinstein, M. Castro, B. Wang, R. Bouley, J.T. Potts, et al., Sustained cyclic AMP production by parathyroid hormone receptor endocytosis, Nat. Chem. Biol. 5 (2009) 734-742, http://dx.doi.org/10.1038 nchembio.206.

[33] A. Fisher, E. Heldman, D. Gurwitz, R. Haring, D. Barak, H. Meshulam, et al., Selective signaling via unique M1 muscarinic agonists, Ann. N. Y. Acad. Sci. 695 (1993) 300-303.

[34] S. Galandrin, G. Oligny-Longpre, M. Bouvier, The evasive nature of drug efficacy: implications for drug discovery, Trends Pharmacol. Sci. 28 (2007) 423-430, http://dx.doi.org/10.1016/j.tips.2007.06.005.

[35] P.R. Gentry, P.M. Sexton, A. Christopoulos, Novel allosteric modulators of G protein-coupled receptors, J. Biol. Chem. 290 (2015) 19478-19488, http://dx. doi.org/10.1074/jbc.R115.662759.

[36] D. Gurwitz, R. Haring, E. Heldman, C.M. Fraser, D. Manor, A. Fisher, Discrete activation of transduction pathways associated with acetylcholine $\mathrm{m} 1$ receptor by several muscarinic ligands, Eur. J. Pharmacol. 267 (1994) 21-31.

[37] K. Haga, A.C. Kruse, H. Asada, T. Yurugi-Kobayashi, M. Shiroishi, C. Zhang et al., Structure of the human M2 muscarinic acetylcholine receptor bound to an antagonist, Nature 482 (2012) 547-551, http://dx.doi.org/10.1038/ nature 10753.

[38] Y. Huang, A. Skwarek-Maruszewska, K. Horre, E. Vandewyer, L. Wolfs, A. Snellinx, et al., Loss of GPR3 reduces the amyloid plaque burden and improves memory in Alzheimer's disease mouse models, Sci. Transl. Med. 7 (2015) 309ra164, http://dx.doi.org/10.1126/scitranslmed.aab3492.

[39] K. Ikeda, T. Kobayashi, T. Kumanishi, R. Yano, I. Sora, H. Niki, Molecular mechanisms of analgesia induced by opioids and ethanol: is the GIRK channel one of the keys? Neurosci. Res. 44 (2002) 121-131.

[40] R. Irannejad, J.C. Tomshine, J.R. Tomshine, M. Chevalier, J.P. Mahoney, J. Steyaert, et al., Conformational biosensors reveal GPCR signalling from endosomes, Nature 495 (2013) 534-538, http://dx.doi.org/10.1038/ nature 12000.

[41] A.W. Kahsai, K. Xiao, S. Rajagopal, S. Ahn, A.K. Shukla, J. Sun, et al., Multiple ligand-specific conformations of the beta2-adrenergic receptor, Nat. Chem. Biol. 7 (2011) 692-700, http://dx.doi.org/10.1038/nchembio.634.

[42] N.C. Kaneider, A. Agarwal, A.J. Leger, A. Kuliopulos, Reversing systemic inflammatory response syndrome with chemokine receptor pepducins, Nat. Med. 11 (2005) 661-665, http://dx.doi.org/10.1038/nm1245.

[43] A. Kebig, E. Kostenis, K. Mohr, M. Mohr-Andra, An optical dynamic mass redistribution assay reveals biased signaling of dualsteric GPCR activators, J. Recept Signal. Transduct Res. 29 (2009) 140-145, http://dx.doi.org/10.1080/ 10799890903047437.

[44] T. Kenakin, Functional selectivity through protean and biased agonism: who steers the ship? Mol. Pharmacol. 72 (2007) 1393-1401, http://dx.doi.org/10. 1124/mol.107.040352.

[45] T. Kenakin, The effective application of biased signaling to new drug discovery, Mol. Pharmacol. (2015), http://dx.doi.org/10.1124/mol.115.099770.

[46] T. Kenakin, C. Watson, V. Muniz-Medina, A. Christopoulos, S. Novick, A simple method for quantifying functional selectivity and agonist bias, ACS Chem. Neurosci. 3 (2012) 193-203, http://dx.doi.org/10.1021/cn200111m.

[47] E. Khajehali, D.T. Malone, M. Glass, P.M. Sexton, A. Christopoulos, K. Leach, Biased agonism and biased allosteric modulation at the CB1 cannabinoid receptor, Mol. Pharmacol. 88 (2015) 368-379, http://dx.doi.org/10.1124/mol 115.099192.

[48] E. Khoury, S. Clement, S.A. Laporte, Allosteric and biased g protein-coupled receptor signaling regulation: potentials for new therapeutics, Front. Endocrinol. (Lausanne) 5 (2014) 68, http://dx.doi.org/10.3389/fendo.2014. 00068.

[49] M.A. Kjelsberg, S. Cotecchia, J. Ostrowski, M.G. Caron, R.J. Lefkowitz, Constitutive activation of the alpha 1B-adrenergic receptor by all amino acid substitutions at a single site. Evidence for a region which constrains receptor activation, J. Biol. Chem. 267 (1992) 1430-1433.

[50] S.L. Kopecky, Effect of beta blockers, particularly carvedilol, on reducing the risk of events after acute myocardial infarction, Am. J. Cardiol. 98 (2006) 1115-1119, http://dx.doi.org/10.1016/j.amjcard.2006.05.039.

[51] S.J. Kotowski, F.W. Hopf, T. Seif, A. Bonci, M. Von Zastrow, Endocytosis promotes rapid dopaminergic signaling, Neuron 71 (2011) 278-290, http:// dx.doi.org/10.1016/j.neuron.2011.05.036.
[52] R.S. Kuna, S.B. Girada, S. Asalla, J. Vallentyne, S. Maddika, J.T. Patterson, et al., Glucagon-like peptide-1 receptor-mediated endosomal cAMP generation promotes glucose-stimulated insulin secretion in pancreatic beta-cells, Am. J Physiol. Endocrinol. Metab. 305 (2013) E161-170, http://dx.doi.org/10.1152/ ajpendo.00551.2012.

[53] J.R. Lane, P.M. Sexton, A. Christopoulos, Bridging the gap: bitopic ligands of G-protein-coupled receptors, Trends Pharmacol. Sci. 34 (2013) 59-66, http:// dx.doi.org/10.1016/j.tips.2012.10.003.

[54] S. Lazareno, V. Dolezal, A. Popham, N.J. Birdsall, Thiochrome enhances acetylcholine affinity at muscarinic M4 receptors: receptor subtype selectivity via cooperativity rather than affinity, Mol. Pharmacol. 65 (2004) 257-266, http://dx.doi.org/10.1124/mol.65.1.257.

[55] R.J. Lefkowitz, S.K. Shenoy, Transduction of receptor signals by beta-arrestins, Science 308 (2005) 512-517, http://dx.doi.org/10.1126/science.1109237.

[56] Y. Li, X. Liu, C. Liu, J. Kang, J. Yang, G. Pei, et al., Improvement of morphine-mediated analgesia by inhibition of beta-arrestin2 expression in mice periaqueductal gray matter, Int. J. Mol. Sci. 10 (2009) 954-963, http://dx. doi.org/10.3390/ijms10030954.

[57] L.M. Luttrell, Minireview: more than just a hammer: ligand bias and pharmaceutical discovery, Mol. Endocrinol. 28 (2014) 281-294, http://dx.doi. org/10.1210/me.2013-1314.

[58] L.M. Luttrell, F.L. Roudabush, E.W. Choy, W.E. Miller, M.E. Field, K.L. Pierce, et al., Activation and targeting of extracellular signal-regulated kinases by beta-arrestin scaffolds, Proc. Natl. Acad. Sci. U. S. A. 98 (2001) 2449-2454 http://dx.doi.org/10.1073/pnas.041604898.

[59] A.E. Mackenzie, G. Milligan, The emerging pharmacology and function of GPR35 in the nervous system, Neuropharmacology (2015), http://dx.doi.org/ 10.1016/j.neuropharm.2015.07.035.

[60] L.T. May, A. Christopoulos, Allosteric modulators of G-protein-coupled receptors, Curr. Opin. Pharmacol. 3 (2003) 551-556.

[61] P.H. Mcdonald, C.W. Chow, W.E. Miller, S.A. Laporte, M.E. Field, F.T. Lin, et al., Beta-arrestin 2: a receptor-regulated MAPK scaffold for the activation of JNK3, Science 290 (2000) 1574-1577.

[62] L.A. Merriam, C.N. Baran, B.M. Girard, J.C. Hardwick, V. May, R.L. Parsons, Pituitary adenylate cyclase 1 receptor internalization and endosomal signaling mediate the pituitary adenylate cyclase activating polypeptide-induced increase in guinea pig cardiac neuron excitability, J. Neurosci. 33 (2013) 4614-4622, http://dx.doi.org/10.1523/JNEUROSCI.499912.2013.

[63] K. Mohr, C. Trankle, E. Kostenis, E. Barocelli, M. De Amici, U. Holzgrabe, Rational design of dualsteric GPCR ligands: quests and promise, $\mathrm{Br}$. J. Pharmacol. 159 (2010) 997-1008, http://dx.doi.org/10.1111/j.1476-5381. 2009.00601.x.

[64] F. Mullershausen, F. Zecri, C. Cetin, A. Billich, D. Guerini, K. Seuwen, Persistent signaling induced by FTY720-phosphate is mediated by internalized S1P1 receptors, Nat. Chem. Biol. 5 (2009) 428-434, http://dx.doi.org/10.1038/ nchembio. 173 .

[65] R. Nygaard, Y. Zou, R.O. Dror, T.J. Mildorf, D.H. Arlow, A. Manglik, et al., The dynamic process of beta(2)-adrenergic receptor activation, Cell 152 (2013) 532-542, http://dx.doi.org/10.1016/j.cell.2013.01.008.

[66] M. Okazaki, S. Ferrandon, J.P. Vilardaga, M.L. Bouxsein, J.T. Potts Jr., T.J. Gardella, Prolonged signaling at the parathyroid hormone receptor by peptide ligands targeted to a specific receptor conformation, Proc. Natl. Acad. Sci. U. S. A. 105 (2008) 16525-16530, http://dx.doi.org/10.1073/pnas.0808750105.

[67] M. Packer, M.R. Bristow, J.N. Cohn, W.S. Colucci, M.B. Fowler, E.M. Gilbert, N.H. Shusterman, The effect of carvedilol on morbidity and mortality in patients with chronic heart failure. U.S. Carvedilol Heart Failure Study Group, N. Engl. J. Med. 334 (1996) 1349-1355.

[68] P.A. Poole-Wilson, K. Swedberg, J.G. Cleland, A. Di Lenarda, P. Hanrath, M. Komajda, J. Lubsen, B. Lutiger, M. Metra, W.J. Remme, C. Torp-Pedersen, A Scherhag, A. Skene, Carvedilol or metoprolol european trial investigators. Comparison of carvedilol and metoprolol on clinical outcomes in patients with chronic heart failure in the Carvedilol Or Metoprolol European Trial (COMET): randomized controlled trial, Lancet 362 (2003) 7-13.

[69] K.M. Raehal, J.K. Walker, L.M. Bohn, Morphine side effects in beta-arrestin 2 knockout mice, J. Pharmacol. Exp. Ther. 314 (2005) 1195-1201, http://dx.doi. org/10.1124/jpet.105.087254.

[70] S. Rajagopal, S. Ahn, D.H. Rominger, W. Gowen-Macdonald, C.M. Lam, S.M. Dewire, et al., Quantifying ligand bias at seven-transmembrane receptors, Mol. Pharmacol. 80 (2011) 367-377, http://dx.doi.org/10.1124/mol.111. 072801.

[71] G.A. Santos, D.A. Duarte, E.S.L.T. Parreiras, F.R. Teixeira, R. Silva-Rocha, E.B. Oliveira, et al., Comparative analyses of downstream signal transduction targets modulated after activation of the AT1 receptor by two beta-arrestin-biased agonists, Front. Pharmacol. 6 (2015) 131, http://dx.doi. org/10.3389/fphar.2015.00131.

[72] J. Shonberg, L. Lopez, P.J. Scammells, A. Christopoulos, B. Capuano, J.R. Lane, Biased agonism at $\mathrm{G}$ protein-coupled receptors: the promise and the challenges-a medicinal chemistry perspective, Med. Res. Rev. 34 (2014) 1286-1330, http://dx.doi.org/10.1002/med.21318.

[73] A.K. Shukla, J.D. Violin, E.J. Whalen, D. Gesty-Palmer, S.K. Shenoy, R.J. Lefkowitz, Distinct conformational changes in beta-arrestin report biased agonism at seven-transmembrane receptors, Proc. Natl. Acad. Sci. U. S. A. 105 (2008) 9988-9993, http://dx.doi.org/10.1073/pnas.0804246105. 
[74] C.D. Strader, T.M. Fong, M.R. Tota, D. Underwood, R.A. Dixon, Structure and function of G protein-coupled receptors, Annu. Rev. Biochem. 63 (1994) 101-132, http://dx.doi.org/10.1146/annurev.bi.63.070194.000533.

[75] A.R. Thomsen, J. Worm, S.E. Jacobsen, M. Stahlhut, M. Latta, H. Brauner-Osborne, Strontium is a biased agonist of the calcium-sensing receptor in rat medullary thyroid carcinoma 6-23 cells, J. Pharmacol. Exp. Ther. 343 (2012) 638-649, http://dx.doi.org/10.1124/jpet.112.197210.

[76] C. Valant, K.J. Gregory, N.E. Hall, P.J. Scammells, M.J. Lew, P.M. Sexton, et al., A novel mechanism of $G$ protein-coupled receptor functional selectivity. Muscarinic partial agonist McN-A-343 as a bitopic orthosteric/allosteric ligand, J. Biol. Chem. 283 (2008) 29312-29321, http://dx.doi.org/10.1074/jbc. M803801200.

[77] C. Valant, J. Robert Lane, P.M. Sexton, A. Christopoulos, The best of both worlds? Bitopic orthosteric/allosteric ligands of g protein-coupled receptors, Annu. Rev. Pharmacol. Toxicol. 52 (2012) 153-178, http://dx.doi.org/10.1146 annurev-pharmtox-010611-134514.

[78] C. Valant, P.M. Sexton, A. Christopoulos, Orthosteric/allosteric bitopic ligands: going hybrid at GPCRs, Mol. Interv. 9 (2009) 125-135, http://dx.doi.org/10. 1124/mi.9.3.6.

[79] J.P. Vilardaga, T.J. Gardella, V.L. Wehbi, T.N. Feinstein, Non-canonical signaling of the PTH receptor, Trends Pharmacol. Sci. 33 (2012) 423-431, http://dx.doi. org/10.1016/j.tips.2012.05.004.

[80] J.P. Vilardaga, F.G. Jean-Alphonse, T.J. Gardella, Endosomal generation of cAMP in GPCR signaling, Nat. Chem. Biol. 10 (2014) 700-706, http://dx.doi. org/10.1038/nchembio.1611.

[81] J.D. Violin, A.L. Crombie, D.G. Soergel, M.W. Lark, Biased ligands at G-protein-coupled receptors: promise and progress, Trends Pharmacol. Sci. 35 (2014) 308-316, http://dx.doi.org/10.1016/j.tips.2014.04.007.

[82] J.D. Violin, S.M. Dewire, D. Yamashita, D.H. Rominger, L. Nguyen, K. Schiller et al., Selectively engaging beta-arrestins at the angiotensin II type 1 receptor reduces blood pressure and increases cardiac performance, J. Pharmacol. Exp. Ther. 335 (2010) 572-579, http://dx.doi.org/10.1124/jpet.110.173005.
[83] J.D. Violin, R.J. Lefkowitz, Beta-arrestin-biased ligands at seven-transmembrane receptors, Trends Pharmacol. Sci. 28 (2007) 416-422, http://dx.doi.org/10.1016/j.tips.2007.06.006.

[84] C. Watson, G. Chen, P. Irving, J. Way, W.J. Chen, T. Kenakin, The use of stimulus-biased assay systems to detect agonist-specific receptor active states: implications for the trafficking of receptor stimulus by agonists, Mol. Pharmacol. 58 (2000) 1230-1238.

[85] V.L. Wehbi, H.P. Stevenson, T.N. Feinstein, G. Calero, G. Romero, J.-P. Vilardaga, Noncanonical GPCR signaling arising from a PTH receptor-arrestin-G $\beta \gamma$ complex, Proc. Natl. Acad. Sci. U. S. A. 110 (2013) 1530-1535, http://dx.doi. org/10.1073/pnas.1205756110.

[86] K.K. Winer, B. Zhang, J.A. Shrader, D. Peterson, M. Smith, P.S. Albert, et al., Synthetic human parathyroid hormone $1-34$ replacement therapy: a randomized crossover trial comparing pump versus injections in the treatment of chronic hypoparathyroidism, J. Clin. Endocrinol. Metab. 97 (2012) 391-399, http://dx.doi.org/10.1210/jc.2011-1908.

[87] J.W. Wisler, S.M. DeWire, E.J. Whalen, J.D. Violin, M.T. Drake, S. Ahn, S.K. Shenoy, R.J. Lefkowitz, A unique mechanism of beta-blocker action: carvedilol stimulates beta-arrestin signaling, Proc. Natl. Acad. Sci. U. S. A. 104 (2007) 16657-16662.

[88] L. Xu, S. Begum, J.D. Hearn, R.O. Hynes, GPR56, an atypical G protein-coupled receptor, binds tissue transglutaminase, TG2, and inhibits melanoma tumor growth and metastasis, Proc. Natl. Acad. Sci. U. S. A. 103 (2006) 9023-9028, http://dx.doi.org/10.1073/pnas.0602681103.

[89] C.H. Yang, H.W. Huang, K.H. Chen, Y.S. Chen, S.M. Sheen-Chen, C.R. Lin, Antinociceptive potentiation and attenuation of tolerance by intrathecal beta-arrestin 2 small interfering RNA in rats, Br. J. Anaesth. 107 (2011) 774-781, http://dx.doi.org/10.1093/bja/aer291. 